\section{Scaling of Glomerular Filtration Rate and SUV for Body Size: The Curious Conflict of Whole-Body Metric Preferences}

TO THE EDITOR: The PET community still uses body weight to calculate SUV despite compelling evidence suggesting that lean body mass should be used instead (thereby deriving the so-called SUL [SUV based on lean body mass] as opposed to SUW [SUV based on body weight]) $(1,2)$. SUW is overestimated in obese individuals because ${ }^{18} \mathrm{~F}$-FDG accumulates minimally in adipose tissue. Both visceral adipose tissue and subcutaneous adipose tissue have SUVs of less than unity (visceral, $\sim 0.8$; subcutaneous, $\sim 0.3$ ) (3). The whole-body SUW is, by definition, unity (4). Not only is a strong correlation between SUW and body weight already well established, but it also has been recently shown, using a different theoretic approach (avoiding the spurious presence of weight in both coordinates), that SUL is preferable to SUW (4). Moreover, almost all publications using SUW have failed to check that the variables they have correlated against SUW do not also correlate with weight. (We ourselves were previously guilty of this oversight with respect to the liver! (5).)

Body surface area has also been suggested as a whole-body metric by which to calculate SUV (1), but this suggestion has justifiably failed to attract much interest considering that body surface area is a 2-dimensional variable rather than a 3-dimensional variable such as distribution volume. So why is it that nuclear nephrologists persist in using body surface area to scale glomerular filtration rate when, again, a 3-dimensional variable would make more sense? Body weight was abandoned for scaling glomerular filtration rate many decades ago because filtration markers such as ${ }^{99} \mathrm{~m} \mathrm{Tc}$-diethylenetriamine pentaacetic acid and ${ }^{125} \mathrm{I}$-iothalamate do not enter adipose tissue, but attempts to replace body weight with 3-dimensional variables such as lean body mass (6), extracellular fluid volume (7), and total body water (8) have been largely ignored, despite widespread criticism of the use of body surface area (9).

So, in summary, both the PET community and the nephrologist community seem reluctant to give up their respective preferred whole-body scaling metrics in favor of lean body mass, which, the evidence suggests, would suit them both. Instead, nephrologists continue to use body surface area, which is the least preferred by the
PET community, whereas the PET community continues to use body weight, which is the least preferred by the nephrology community! One difficulty to resolve, if we were to aim for unity, is the best formula to use for estimating lean body mass $(2,10)$.

\section{REFERENCES}

1. Sugawara Y, Zasadny KR, Neuhoff AW, Wahl RL. Reevaluation of the standardized uptake value for FDG: variations with body weight and methods for correction. Radiology. 1999;213:521-525.

2. Tahari AK, Chien D, Azadi JR, Wahl RL. Optimum lean body formulation for correction of standardized uptake value in PET imaging. J Nucl Med. 2014;55: 1481-1484.

3. Christen T, Sheikine Y, Rocha VZ, et al. Increased glucose uptake in visceral versus subcutaneous adipose tissue revealed by PET imaging. JACC Cardiovasc Imaging. 2010;3:843-851.

4. Keramida G, Hunter J, Dizdarevic S, Peters AM. The appropriate whole-body index on which to base standardized uptake value in 2-deoxy-2-[ $\left.{ }^{18} \mathrm{~F}\right]$ fludeoxyglucose PET. Br J Radiol. 2015;88:20140520.

5. Keramida G, Potts J, Bush J, Dizdarevic S, Peters AM. Hepatic steatosis is associated with increased hepatic FDG uptake. Eur J Radiol. 2014;83: 751-755.

6. Peters AM, Glass DM, Love S, Bird NJ. Estimated lean body mass is more appropriate than body surface area for scaling glomerular filtration rate and extracellular fluid volume. Nephron Clin Pract. 2010;116:c75-c80.

7. Peters AM, Perry L, Hooker CA, et al. Extracellular fluid volume and glomerular filtration rate in 1,878 healthy potential renal transplant donors: effects of age, gender, obesity and scaling. Nephrol Dial Transplant. 2012;27: 1429-1437.

8. Eriksen BO, Melsom T, Mathisen UD, Jenssen TG, Solbu MD, Toft I. GFR normalized to total body water allows comparisons across genders and body sizes. J Am Soc Nephrol. 2011;22:1517-1525.

9. Turner ST, Reilly SL. Fallacy of indexing renal and systemic hemodynamic measurements for body surface area. Am J Physiol. 1995;268:R978-R988.

10. Erselcan T, Turgut B, Dogan D, Ozdemir S. Lean body mass-based standardized uptake value, derived from a predictive equation, might be misleading in PET studies. Eur J Nucl Med Mol Imaging. 2002;29:1630-1638.

Georgia Keramida
A. Michael Peters*
*Royal Sussex County Hospital
Room SP205, Southpoint, Eastern Rd.
Brighton BN2 5BE, U.K.
E-mail: a.m.peters@bsms.ac.uk

Published online Jun. 9, 2016.

DOI: $10.2967 /$ jnumed.116.176800 